\title{
Antecedents of War: The geopolitics of low oil prices and decelerating financial liquidity
}

\author{
Hany Abdel-Latif ${ }^{a, c, *}$, Mahmoud El-Gamal ${ }^{\mathrm{b}, \mathrm{c}}$ \\ ${ }^{a}$ Swansea University, UK \\ ${ }^{b}$ Rice University, USA \\ ${ }^{c}$ Economic Research Forum
}

\begin{abstract}
We investigate the joint dynamics of oil prices, financial liquidity and geopolitical risk, within a multi-country global vector-autoregressive (GVAR) model. We find that low oil prices are expected to trigger higher levels of geopolitical risk, and that decelerating financial liquidity serves as an accelerator.

Keywords: Geopolitics, Global Liquidity, Oil Prices, Global VAR

JEL code: C32, E17, F44, F47, O53, Q43
\end{abstract}

*Corresponding author: Hany Abdel-Latif, School of Management, Swansea University, Bay Campus, Fabian Way Swansea SA1 8EN UK (E-mail: h.abdel-latif@swansea.ac.uk). 


\section{Introduction}

Oil prices plunged from a peak of $\$ 115$ per barrel in June 2014 to under $\$ 35$ at the end of February 2016. Although similar drops were observed in the past (mid 1980s and 2008-09), this time is different because it may usher the end 5 of petrodollars. The link between global financial liquidity and oil prices has been studied extensively (Jo, 2014, for example). However, recent studies, such as Alsalman (2016), have suggested that the previously strong link between financial and oil market bubbles broke down in the 2000s. Ratti and Vespignani (2013) found evidence of the reverse causal link: unanticipated increases in global liquidity can lead to statistically significant increases in real oil prices.

We contribute to this literature by including geopolitical risk as a third factor in the multivariate analysis of oil prices and global financial liquidity. There is a growing literature investigating the causal direction from intensified geopolitical risk to oil prices, although Blomberg et al. (2009) found that declining market power of OPEC has reduced the magnitudes of geopolitical risk premia in oil prices. Lee (2016) argued that major oil producers, especially in the Middle East, remain particularly attractive targets for terrorists, because significant economic harm can result from a major disruption of oil production and/or transport from the region. Noguera-Santaella (2016) found a strong positive effect of geopolitical strife on oil prices.

We add to this literature by using a continuous measure of geopolitical risk, and studying its joint causal links with oil prices and global financial liquidity (through petrodollar recycling and its reversal). To the best of our knowledge, this is the first paper to consider all three global variables simultaneously. The self perpetuating cycle for all three variables was studied in El-Gamal and Jaffe (2009), who noted the joint roles of geopolitics and financial liquidity in oil price surges in 1973, 1979, and 2003, and the reverse causal link from low oil prices to geopolitical risk in 1990 and 2001. 
The remainder of this paper is organised as follows: Section 2 discusses data and empirical methodology, Section 3 summarizes our empirical results, and Section 4 provides some brief concluding remarks.

\section{Methodology and Dataset}

We employ a global vector autoregressive (GVAR) model, which allows us to study the dynamic relationships amongst oil prices, financial liquidity, and geopolitical risks in a multi-country framework. The model allows for multivariate transmission and feedback at country and global levels. The GVAR model can be presented as follows:

$$
\mathbf{x}_{i t}=\sum_{l=1}^{p_{i}} \boldsymbol{\Phi}_{i l} \mathbf{x}_{i, t-l}+\sum_{l=1}^{q_{i}} \mathbf{A}_{i l} \mathbf{x}_{i, t-l}^{*}+\epsilon_{i t}
$$

for country $i=0,1,2, \ldots, N$ and time period $t=1,2, \ldots, T$, where $\boldsymbol{\Phi}_{i l}$ and $\mathbf{A}_{i l}$ are matrices of unknown parameters, and $\epsilon_{i t}$ are uncorrelated idiosyncratic shocks. The GVAR model incorporates two sets of lagged variables: domestic variables $\mathbf{x}$ and foreign variables $\mathbf{x}^{*}$, where $p_{i}$ and $q_{i}$ are the lag orders for country $i$. Foreign variables are assumed to be weakly exogenous, and include country-specific foreign variables as well as global variables. Country-specific foreign variables are cross-sectional averages of the domestic variables in other countries. We use bilateral trade-based weights $w_{i j}$ for this purpose:

$$
\mathbf{x}_{i t}^{*}=\sum_{j=0}^{N} w_{i j} \mathbf{x}_{j t}
$$

Our global variables include oil prices, geopolitical risk index, and global financial liquidity. These variables are assumed endogenous only in the UScountry model, and weakly exogenous for all other countries, which can only influence the variables collectively. The model is estimated on a country-by- 
into a single global model, which can be used to stimulate different shocks in the system, c.f. Dovern and Huber (2015) for details.

We use quarterly data from 1979Q1 to2017Q2 for 70 countries. Domestic variables include real GDP, investment (measured as gross capital formation), and international reserves. The bulk of this data is obtained through DataStream, while bilateral trade data are obtained from the IMF direction of trade statistics (DOTS) database. We use Brent price of crude oil (in USD per Barrel) for oil price, and the BIS series (Bank for International Settlements, March 2017) on credit from all sectors to the private non-financial sector as our measure of global financial liquidity. For our measure of global geopolitical risk, we use the index constructed by Caldara and Iacoviello (2016).

\section{Empirical Results}

\subsection{Diagnostic Tests}

Using the ADF unit root test, we found individual series to be integrated of order one. Therefore, we proceed to estimate a set of country-specific vector error correction (VECX) models, with ' $\mathrm{X}$ ' denoting weakly exogenous foreign variables. To test for the presence of cointegration, we used the maximum eigenvalue and trace statistics at the $5 \%$ significance level, and cocluded that all estimated country-specific models have either one or two cointegrating relationships. In addition, according to the F-statistics tests of residuals' serial correlation in individual country VECMX models, we failed to reject the null hypothesis of no serial correlation at the $5 \%$ significance level.

We also confirmed the weak exogeneity assumption of foreign variables by failing to reject the significance of estimated error-correction terms in auxiliary regressions, wherein foreign and global variables were dependent variables. Finally, using the persistence profiles, we were able to confirm the validity of 
our estimated cointegrating vectors by illustrating fast convergence to long term

\subsection{Dynamic Analysis}

Results are shown graphically in terms of generalised impulse response functions (GRIFs) from our estimated GVAR(2) model. We consider shocks to each of our three global variables (oil price, financial liquidity, and geopolitical risks) and track the response of the other two variables. We plot the median GIRF and its $95 \%$ confidence interval from 2000 bootstrap replications.

The pair of GIRF graphs for the impacts on global liquidity and geopolitical risk from a one standard deviation negative shock in oil prices are shown in so Fig. 1. The left panel shows that, starting one year after the shock, geopolitical risk increases significantly, around $4 \%$, and persists in response to a one s.d. negative oil price shocks. This indicates that periods of low oil prices contribute to increased geopolitical strife. The right panel shows that global liquidity declines significantly (in the order of $10 \%$ ), both immediately and persistently, 85 in response to a one s.d. negative oil price shock. This indicates that a decline in oil prices reduces or reverses petrodollar flows to the international financial system, thus resulting in reduced global financial liquidity.

\footnotetext{
${ }^{1}$ Detailed test results are omitted for space considerations but available upon request.
} 
Figure 1: Impulse $=$ One s.d. Negative Shock to Oil Price

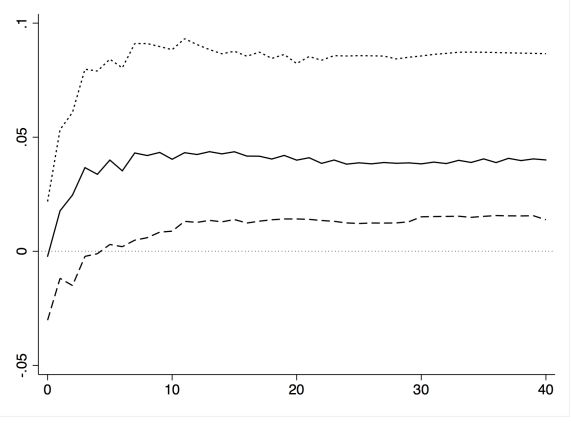

Geopolitical Risk GIRF

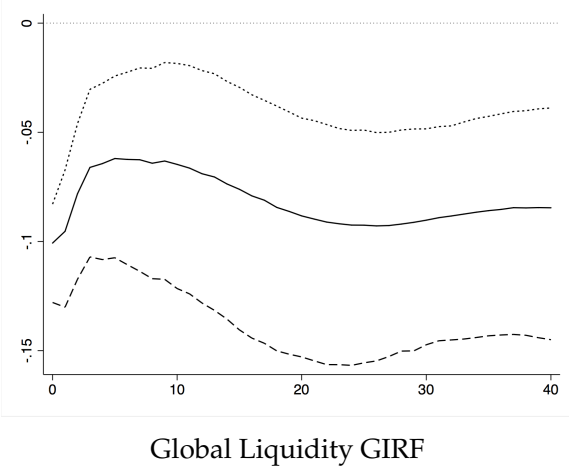

The pair of GIRFs for the impacts on global liquidity and oil prices from a one standard deviation positive shock in global geopolitical risk are shown in Fig. 2. The left panel shows a persistently negative (approximately $0.2 \%$ ) but statistically insignificant decline in global liquidity. The right panel shows a persistently positive (approximately 1.5\%) and statistically significant response of oil prices to a one s.d. positive shock in geopolitical risk. This accords with our hypothesis on oil price and geopolitical risk cycles: lower oil prices trigger higher geopolitical risk (as we have seen in the left panel of 1 ), and the latter leads to later increases in oil prices, perpetuating the endogenous cycle discussed in El-Gamal and Jaffe (2009).

Figure 2: Impulse $=$ One s.d. Positive Shock to Geopolitical Risk Index
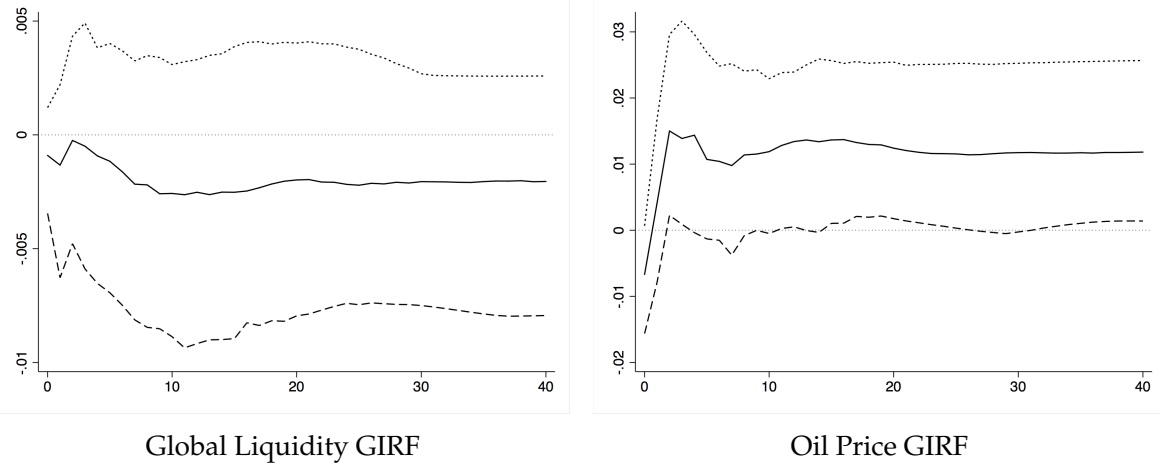
The pair of GIRFs for the impacts on geopolitical risk and oil prices from a one s.d. negative shock in global financial liquidity are shown in Fig. 3 The left panel shows that geopolitical risk index responds positively and persistently (at approximately $2.5 \%$ ), albeit mostly statistically insignificantly, to the negative liquidity shock. The right panel shows that oil prices are likely to drop persistently (by approximately 5\%) in response to the negative shock in global financial liquidity. The impulse response in oil prices is statistically significant for approximately 3 years, during which it appears that the investment-commodityclass and/or speculative-trade channel from global financial liquidity to oil prices is hampered by the stipulated negative liquidity shock.

Figure 3: Impulse $=$ One s.d. Negative Shock to Global Financial Liquidity

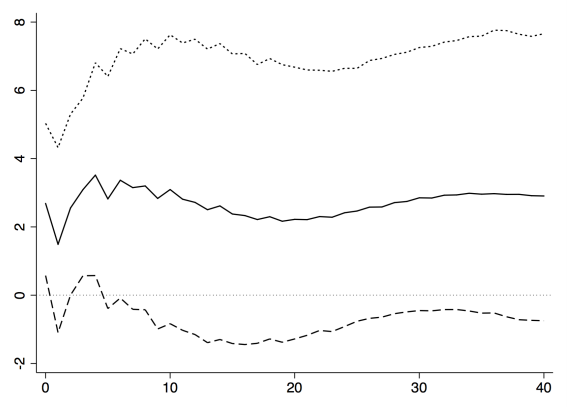

Geopolitical Risk GIRF

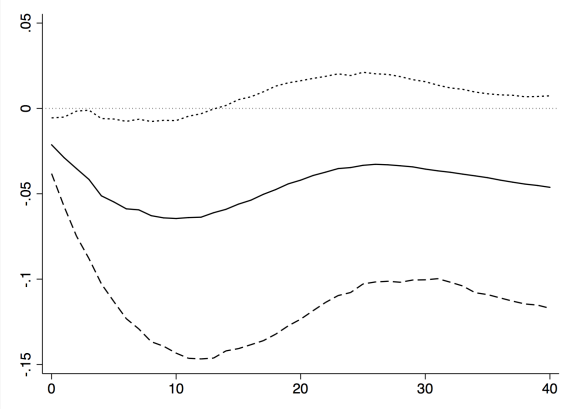

Oil Price GIRF

Finally, inspired by our earlier findings, we consider the impacts of likely combined shocks of two global variables on the third. In particular, we examine the effect of a simultaneous negative shock to global financial liquidity and heightened geopolitical risk as well as the impact of a simultaneous negative shock to financial liquidity and oil prices. The sobering conclusion of the GIRF analysis to individual and simultaneous shocks that resemble the current environment is that we should expect continuation of the current forecast of low oil prices, decelerating or declining financial liquidity, and medium-level heightening of geopolitical risk. Of course, were a major shock to geopolitical risk to materialize, it may have a strong positive effect on oil prices and financial 
liquidity, through the petrodollar recycling channel. Ominously, if oil prices were to drop significantly from their current levels, this may trigger that surge in geopolitical risk, which may plant the seeds for higher oil prices in a later period. In the meantime, a major financial liquidity shock due to significant monetary tightening, either pre-emptively to enhance monetary policy effectiveness during the next global recession, or in response to a potential up-tick in inflation, is unlikely to have a significant effect on geopolitical risk and oil prices. In this regard, financial liquidity merely serves as a pro-cyclical accelerator for oil price movements during periods of high prices (e.g. during the decade 2003-2013), as well as low prices (e.g. in the current period), through the commodity-investment-class and/or speculative trading channels.

Figure 4: Global Variable Responses to Select Combined Shocks

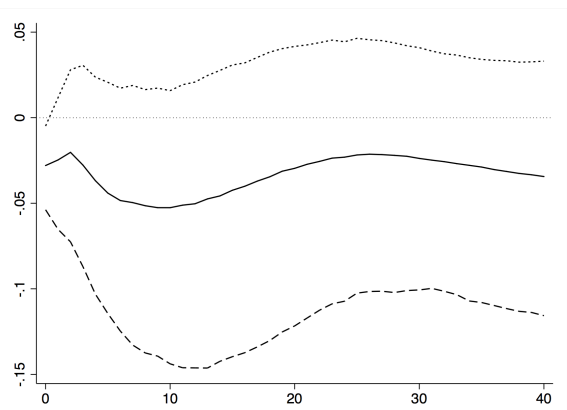

Oil Price GIRF (simultaneous 1 s.d. each: (i) negative shock to financial liquidity, and (ii) positive shock to geopolitical risk)

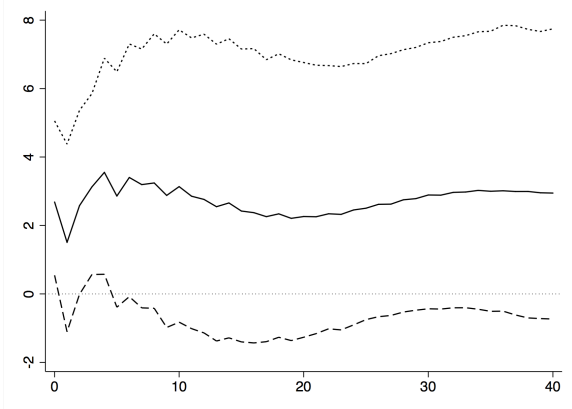

Geopolitical Risk GIRF (simultaneous 1 s.d. each:

(i) negative shock to financial liquidity, and (ii) negative shock to oil prices)

\section{Conclusion}

Our GVAR model took the U.S. to be the only country that can unilaterally influence the three global variables (oil prices, financial liquidity, and geopolitical risk), while the large number of countries in our sample were allowed collectively to influence those variables. Generalized impulse response functions from the GVAR model confirm our hypothesis that a negative shock to oil prices results in higher geopolitical risk and lower global financial liquidity, 
as petrodollar recycling decelerates or reverses direction. The GIRFs also show that a positive shock to geopolitical risk results in higher oil prices. Thus, we reconfirm the perpetuation of the cycle of low oil prices (e.g. in the late 1980s) leading to geopolitical strife (e.g. first Iraq War), which, in turn, leads to higher oil prices. We also confirm the catalytic role of financial liquidity in accelerating oil price bubbles and crashes, as petrodollar recycling fuels speculative demand for all commodities, including oil.

\section{References}

Alsalman, Z., 2016. Oil price uncertainty and the u.s. stock market analysis based on a garch-in-mean var model. Energy Economics 59, 251-60.

Bank for International Settlements, March 2017. BIS Statistical Bulletin. Technical Report. Bank for International Settlements.

Blomberg, B., Hess, G., Hackson, H., 2009. Terrorism and returns to oil. Economics and Politics 21, 409-32.

150 Caldara, D., Iacoviello, M., 2016. Measuring geopolitical risk. Federal Reserve Board of Governors.

Dovern, J., Huber, F., 2015. Global prediction of recessions. Economics Letters $133,81-84$.

El-Gamal, M., Jaffe, A., 2009. Oil, Dollars, Debt, and Crises: The Global Curse of Black Gold. Cambridge University Press, New York.

Jo, S., 2014. The effects of oil price uncertainty on global real economic activity. Journal of Money, Credit and Banking 46, 1113-35.

Lee, C., 2016. Oil and terrorism: Uncovering the mechanisms. Journal of Conflict Resolution , 1-26.

160 Noguera-Santaella, J., 2016. Geopolitics and the oil price. Economic Modelling $52,301-309$. 
Pesaran, M.H., Shin, Y., 1996. Cointegration and speed of convergence to equilibrium. Journal of econometrics 71, 117-143.

Ratti, R., Vespignani, J., 2013. Why are crude oil prices high when global activity is weak? Economics Letters 121, 133-6. 